\title{
Differential Expression of Synapsins I and II among Rat Retinal Synapses
}

\author{
James W. Mandell, ${ }^{1}$ Andrew J. Czernik, ${ }^{2}$ Pietro De Camilli, ${ }^{3}$ Paul Greengard, ${ }^{2}$ and Ellen Townes-Anderson' \\ 'Department of Physiology and Biophysics, Cornell University Medical College, New York, New York 10021, '2Laboratory of \\ Molecular and Cellular Neuroscience, The Rockefeller University, New York, New York 10021, and ${ }^{3}$ Department of Cell \\ Biology, Yale University School of Medicine, New Haven, Connecticut 06510
}

The synapsins are a family of synaptic vesicle-associated phosphoproteins thought to regulate the availability of vesicles for neurotransmitter release. In order to assess variability of synapsin isoform expression, we compared the localization of synapsins $\mathrm{la}, \mathrm{lb}, \mathrm{Ila}$, and $\mathrm{Ilb}$ in the inner plexiform layer of the rat retina. Double labeling in conjunction with confocal fluorescence and electron microscopy allowed imaging of synapsin I and II immunoreactivity within single presynaptic terminals. No qualitative differences were observed between expression of the $a$ and $b$ isoforms of synapsin $I$ in individual terminals; likewise, the $a$ and $b$ isoforms of synapsin II were identically distributed. In contrast, marked differences were seen upon comparison of synapsin I and synapsin II expression in single terminals. Our results indicate the existence of three classes of presumed ama-

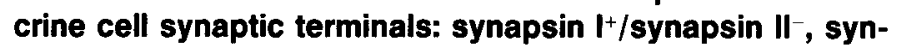
apsin $\mathrm{I}^{-} /$synapsin $\mathrm{I}^{+}$, and synapsin $\mathrm{I}^{+} /$synapsin $\mathrm{II}^{+}$. Each class of synapse has a different distribution among five IPL sublayers, suggesting that they represent different subpopulations of amacrine cells. Double labeling with an antibody to choline acetyltransferase indicates that synapsin $1-/ I^{+}$ terminals may be those of cholinergic amacrine cells. Furthermore, all synapsin $11+$ terminals appear to be distinct from those expressing the GABA synthetic enzyme glutamic acid decarboxylase. The observed variations in synapsin content suggest the existence of presynaptic terminal heterogeneity that is not apparent from conventional morphological studies.

Synapses of most brain neurons exhibit a considerable degree of structural uniformity in spite of the complex and diverse functions attributed to them. The most widely accepted synapse classification system divides cortical synapses into two morphological classes, based on the appearance of synaptic membrane densities and vesicle shape in aldehyde-fixed preparations (Gray, 1959). These two classes, Gray's type I and type II, have,

\footnotetext{
Received July 16, 1991; revised Nov. 22, 1991; accepted Dec. 6, 1991.

This work was supported by NIH Grants EY06135 (E.T.-A.) and MH39327 (P.G.). P.D.C. is supported by a Muscular Dystrophy Association grant. J.W.M is the recipient of a Life and Health Insurance Medical Research Fund Scholarship. We thank Dr. Michael Browning for the synapsin IIa/IIb monoclonal antibodies, Dr. Peter MacLeish for the Sal-1 antibody, and Dr. Michele Solimena for the human anti-GAD serum.

Correspondence should be addressed to Dr. James W. Mandell, Department of Physiology and Biophysics, Cornell University Medical College, 1300 York Avenue, New York, NY 10021.

Copyright (C) 1992 Society for Neuroscience $0270-6474 / 92 / 121736-14 \$ 05.00 / 0$
}

for the most part, been shown to correspond to excitatory and inhibitory synapses, respectively (Uchizono, 1965; Gray, 1969). Since synaptic transmission in the brain involves many other functional variables, such as the magnitude, frequency, and temporal pattern of neurotransmitter release, it seems likely that additional structural corrclates also cxist for thcse parameters. Morphometric analyses of the rat visual cortex (Peters et al., 1990), avian anteroventral cochlear nucleus (AVCN) (Gulley et al., 1978), and LGN (Rapisardi and Lipsenthal, 1984) indicated the existence of synapses that could not be placed neatly within the type I/II classification system and required additional categories. A more recent study of the AVCN using rapid freezing techniques revealed even more variability in the details of synaptic structure (Tatsuoka and Reese, 1989). Such structural diversity must arise from variations in the molecular components of the synapse. Elucidation of these molecular variations is a necessary step toward understanding the relationship between synaptic structure and function.

In the present study, we have investigated the molecular heterogeneity of presynaptic terminals in the vertebrate retina by examining the localization of the synapsins, a family of synaptic vesicle proteins (SVPs). Many investigators have identificd molecules associated with synaptic vesicles, the predominant organelle of nerve terminals (reviewed by Reichardt and Kelly, 1983; De Camilli and Jahn, 1990; Südhof and Jahn, 1991). Some SVPs seem to be common to all synapses that contain small synaptic vesicles. They include protein p65 (synaptotagmin; Matthew et al., 1981; Perin et al., 1990), synaptophysin (protein p38; Jahn et al., 1985; Wiedenmann and Franke, 1985), SV2 (Buckley and Kelly, 1985), and protein p29 (Baumert et al., 1990). They are all intrinsic proteins of the vesicle membrane. Other SVPs are differentially expressed among neuronal subpopulations. These include VAMP-1/VAMP-2/synaptobrevin, a group of intrinsic membrane proteins (Trimble et al., 1988, 1990; Baumert et al., 1989; Elferink et al,, 1989), SVP 36 and SVP 65 (Obata et al., 1987), and the synapsins (Südhof et al., 1989).

The synapsins are a family of four closely related ncuronspecific phosphoproteins (synapsins Ia, Ib, IIa, and IIb), all of which are peripheral membrane proteins that bind to the cytoplasmic surface of small synaptic vesicles. Synapsin I associates with synaptic vesicles (Schiebler et al., 1986) and actin filaments (Bahler and Greengard, 1987; Petrucci and Morrow, 1987) in a phosphorylation-dependent manner. Structural studies suggest that synapsin $\mathrm{I}$, by linking vesicles to each other and to actin filaments, may be responsible for the clustering of ves- 
icles at the active zone (Landis et al., 1988; Hirokawa et al., 1989). These data as well as physiological assays (Llinas et al., 1985; Hackett et al., 1990; Lin et al., 1990; Nichols et al., 1990) suggest that synapsin I regulates the availability of synaptic vesicles for neurotransmitter release.

The four synapsins are encoded for by two genes, one for $\mathrm{Ia} / \mathrm{b}$ and the other for IIa/b (Südhof et al., 1989). Primary transcripts from the two genes are differentially spliced to give rise to the $\mathrm{a}$ and $\mathrm{b}$ isoforms. The four proteins have common as well as unique domains, suggesting that their functions are related, yet distinct. Preliminary studies indicated the existence of variations in the expression of the synapsins in different brain regions. Mossy fiber terminals in the hippocampus contained all four synapsins, whereas cerebellar Purkinje cell axon terminals were shown to lack synapsin IIa and some terminals in the nucleus of the trapezoid body lacked synapsin IIb (Südhof et al., 1989).

We have previously shown that synapses formed by retinal photoreceptors and bipolar cells, called ribbon synapses because of their distinct ultrastructure, differ from conventional synapses in that they lack both synapsins I and II (Mandell et al., 1990a). In addition, we demonstrated that synapsins I and II were differentially expressed among conventional synapses in the retinal inner plexiform layer (IPL). Whereas synapsin Ia and Ib immunoreactivity was distributed across most of the IPL width, synapsin IIa and IIb immunoreactivity was found to be concentrated in three distinct strata (Mandell et al., 1990a).

Because the resolution afforded by conventional immunofluorescence microscopy was not sufficient to determine the relative expression of synapsins I and II within individual nerve terminals, we have now utilized two high-resolution techniques, confocal fluorescence microscopy and immunoelectron microscopy. Our analysis of the differential expression of synapsins I and II suggested a classification scheme for retinal synapses. We have related the distribution of each class of synapse to the laminar organization of the IPL. In addition, we have compared the localization of synapsin $\mathrm{II}^{+}$terminals to that of cholinergic and GABAergic processes identified by immunolocalization of their synthetic enzymes.

Portions of this work were presented in abstract form (Mandell et al., 1990b).

\section{Materials and Methods}

Antibodies. The anti-synapsin antibodies used in this study have been previously characterized (De Camilli et al., 1983a; Browning et al., 1987; Südhof et al., 1989). Their specificity in rat retina has been demonstrated by immunoblotting and immunofluorescence (Mandell et al., 1990a). For immunofluorescence, they were used at the following dilutions: G-115, 1:50; G-281, 1:50; 10.22 (culture supernatant), 1:20. For protein A-gold labeling: $I_{4}, 1: 50 ; \mathrm{G}-281,1: 50$. For double-label immunogold labeling: $\mathbf{I}_{4}, 1: 50 ; 19.31+19.41$ (culture supernatants), 1:20; normal rabbit serum, 1:50; Sal-1 (irrelevant $m A b$ ), 1:20. The rat monoclonal antibody against choline acetyltransferase (CAT; Boehringer Mannheim, Indianapolis, IN) was used at a concentration of $2 \mu \mathrm{g} / \mathrm{ml}$. The anti-glutamic acid decarboxylase (GAD) antiserum was a gift from Dr. Michele Solimena, Yale University School of Medicine. It was obtained from a patient with stiff-man syndrome, a disease in which autoantibodies against GAD are sometimes present. The specificity of the antiserum (patient 1) for rat GAD has been characterized (Solimena et al., 1988). It was used at a dilution of $1: 200$.

Rhodamine- and fluorescein-conjugated secondary antibodies were from Organon Teknika/Cappel (Malvern, PA). Texas red-conjugated goat anti-mouse IgG was from Jackson Laboratories (Bar Harbor, ME). All were used at a final dilution of 1:40. Colloidal gold-conjugated protein A $(5 \mathrm{~nm})$, goat anti-mouse IgG $(5 \mathrm{~nm})$, and goat anti-rabbit IgG $(10 \mathrm{~nm})$ were from Janssen (Belgium) and were used at a final dilution of $1: 30$.
Conventional immunofluorescence. Light-adapted male or female Sprague-Dawley rats were given a lethal dose of Chloropent (Ft. Dodge Labs, Ft. Dodge, IA) or were killed by $\mathrm{CO}_{2}$ intoxication. For synapsin immunocytochemistry, frozen sections of rat retina were prepared and labeled as previously described (Mandell et al., 1990a). Retinas for choline acetyltransferase immunofluorescence were fixed in $4 \%$ formaldehyde, $0.2 \%$ picric acid in $0.1 \mathrm{~m}$ phosphate buffer (PB), $\mathrm{pH} 7.4$. Optimal CAT and synapsin double-label immunofluorescence was obtained with sequential incubations. Anti-CAT was applied in $0.45 \mathrm{M}$ $\mathrm{NaCl}, 20 \mathrm{~mm} \mathrm{~PB}, 17 \%$ whole goat serum (GSDB), without Triton $\mathrm{X}-100$ for 12-24 hr at room temperature. After rinsing in PBS three times for $15 \mathrm{~min}$ each, fluorescein-conjugated mouse anti-rat (diluted in GSDB) was applied for $3 \mathrm{hr}$. After another PBS rinse, the sections were incubated for $3 \mathrm{hr}$ in anti-synapsin IIa (G-281) diluted in GSDB with $0.3 \%$ Triton $X-100$. After rinsing three times in wash buffer $(0.5 \mathrm{M} \mathrm{NaCl}, 20 \mathrm{~mm}$ $\mathrm{PB}, 0.3 \%$ Triton $\mathrm{X}-100$ ), the sections were incubated in rhodamineconjugated goat anti-rabbit diluted in GSDB with $0.3 \%$ Triton X-100 for $1 \mathrm{hr}$. Final rinsing was in wash buffer (three times for $15 \mathrm{~min}$ ) followed by one rinse with $5 \mathrm{~mm}$ PB. Sections were coverslipped with 90\% glycerol, 10\% PBS, $2.5 \%$ (w/v) 1,4-diazobicyclo[2,2,2]-octane (Johnson et al., 1982). Black and white photomicrographs were taken with Kodak T-Max 400 film (developed with D-76 diluted 1:1).

Confocal microscopy. For confocal microscopy, fixed retinas were processed either whole or as thick $(40-70 \mu \mathrm{m})$ sections. The latter were prepared by flattening a whole fixed retina, receptor side up, on a Tefion surface and slicing with a Mcllwain tissue chopper. This method provided superior preservation of inner plexiform layer structurc. Immunostaining was as previously described except that incubation in primary and secondary antibodies was carried out on free-floating sections or whole retinas in glass test tubes for 12-24 $\mathrm{hr}$.

A Sarastro Phoibos 1000 laser confocal microscope system (Sarastro, Inc., Ypsilanti, MI) was used to obtain single- and dual-label images of synapsin-immunostained whole mounts or thick sections. A $100 \times$ oil immersion objective [numerical aperture (NA) 1.4] was used to obtain vertical sections and a $40 \times$ oil immersion objective (NA 1.3) for horizontal sections of whole-mounted retinas. For single-label fluorescein imaging, a $488 \mathrm{~nm}$ excitation filter and a $515 \mathrm{~nm}$ barrier filter were used. For dual labeling of fluorescein and rhodamine or Texas red immunostained tissue, the laser was operated at maximum power in order to maximize the intensity of the $590 \mathrm{~nm}$ line. A $565 \mathrm{~nm}$ dichroic beam splitter was used with a $515 \mathrm{~nm}$ barricr filter for the fluorescein channel, and 590 or $630 \mathrm{~nm}$ barrier filters for rhodamine or Texas red, respectively. A small degree of bleed-through of the fluorescein signal was seen in the rhodamine channel (see Fig. 5). This problem was minimized by use of Texas red (a longer-wavelength emitter) as the second fluorophore (see Fig. 3). Unprocessed $512 \times 512$ pixel images were obtained and stored on hard disk or tape drive. For the dual-label color image, the MERGE program was used to combine the two channels (fluorescein and Texas red). Vanis 3-D reconstruction software was used to make a single projection of serial sections. Photographs were taken directly from the computer monitor with T-Max 100 or Ektachrome 160 film. In all dual-label experiments, photographic prints of the two fluorescence channels were exposed and processed identically. To quantify nerve terminals according to their expression of synapsins I and II, acetate sheets were placed over black and white prints of the two separate fluorescence images. The positions of fluorescent puncta, thought to represent presynaptic terminals, were marked on each sheet. The sheets were then aligned by eye using puncta common to both channels. Puncta were classified as synapsin $\mathrm{I}^{+} /$synapsin $\mathrm{II}^{-}$, synapsin $\mathrm{I}^{-} /$synapsin $\mathrm{II}^{+}$, or synapsin $\mathrm{I}^{+} /$synapsin $\mathrm{II}^{+}$and then counted.

Immunoelectron microscopy. Postembedding techniques, including labeling of ultrathin cryosections or of LR White-embedded retinal sections did not adequately preserve synapsin immunoreactivity (although other antigens were successfully detected). Therefore, we turned to immunolabeling of agarose-embedded lysed synaptosomes, a technique that preserves synapsin immunoreactivity as well as presynaptic ultrastructure and allows access of gold-labeled antibodies into the presynaptic terminal (De Camilli et al., 1983b). The protocol was as previously describcd (De Camilli et al., 1983b) except that each homogenate was prepared from six rat retinas. Fixed agarose blocks were treated with $1 \% \mathrm{NaBH}_{4}$ in $0.1 \mathrm{M} \mathrm{PB}$ for $15 \mathrm{~min}$, rinsed three times for $15 \mathrm{~min}$ each with $0.1 \mathrm{M} \mathrm{PB}$, and placed in GSDB (without Triton X-100) for $1 \mathrm{hr}$ to block nonspecific binding. Primary antibodies were diluted in GSDB. For double-label experiments, both antibodies were applied simultaneously. Blocks were incubated $12 \mathrm{hr}$ at $4^{\circ} \mathrm{C}$ with rotation. After rinsing five times for 15 min each in $0.5 \mathrm{M} \mathrm{NaCl}, 20 \mathrm{mM} P B$, blocks 

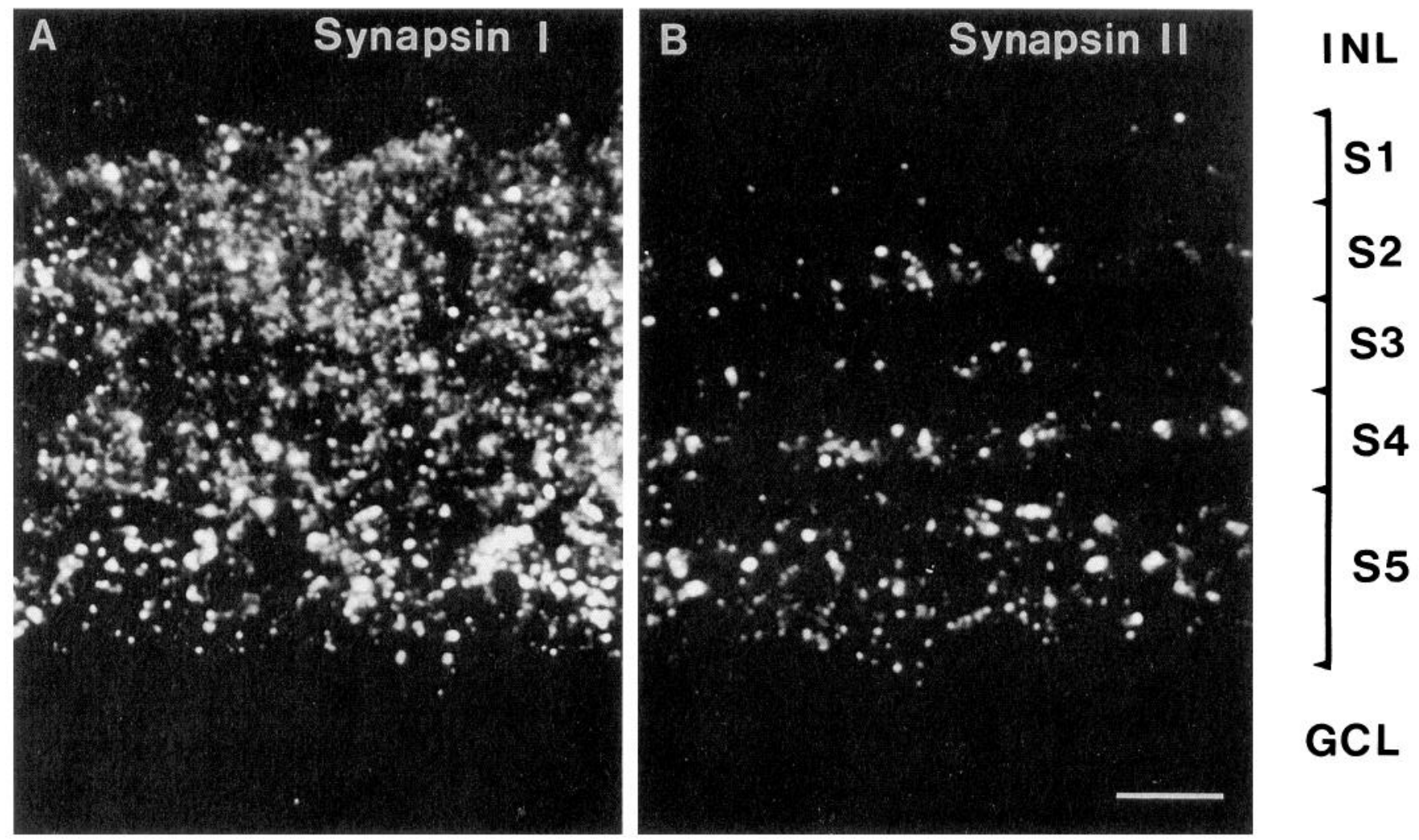

Figure 1. Confocal microscopy of synapsin I and synapsin II immunofluorescence in the rat IPL. A series of vertical confocal sections were reconstructed to image immunoreactive puncta contained within a $4 \mu \mathrm{m}$ thickness of retina. Synapsin I-immunoreactive puncta, ranging from 0.2 to $2 \mu \mathrm{m}$ in size, are distributed throughout the five IPL sublayers, $S 1-S 5(A)$. In contrast, synapsin II-immunoreactive puncta are heavily concentrated within $S 2, S 4$, and $S 5(B)$. INL, inner nuclear layer; $G C L$, ganglion cell layer. Antibodies used: synapsin I, G-115 (Ia/b) and fluorescein; synapsin II, G-281 (IIa) and fluorescein. Scale bar, $10 \mu \mathrm{m}$.

were incubated in protein A-gold in PBS with 1\% BSA for single labeling or goat anti-mouse conjugated to $5 \mathrm{~nm}$ gold and gold anti-rabbit conjugated to $10 \mathrm{~nm}$ gold in PBS with 1\% BSA for double labeling. After a $6 \mathrm{hr}$ incubation at room temperature, blocks were washed five times for $15 \mathrm{~min}$ each with $0.5 \mathrm{M} \mathrm{NaCl}, 20 \mathrm{~mm} \mathrm{~PB}$; rinsed in $0.1 \mathrm{M} \mathrm{PB}$; and fixed in $2 \%$ glutaraldehyde for $30 \mathrm{~min}$. A rinse in cacodylate buffer was followed by postfixation in $1 \% \mathrm{OsO}_{4}$, dehydration in ethanol and propylene oxide, and embedding in an Epon 812 mixture. Thin sections were stained with uranyl acetate and lead citrate and viewed with a JEOL CXII electron microscope.

The gold-labeled secondary antibodies were tested for possible crossreactivity as follows: $10 \mu \mathrm{l}$ of normal rabbit or mouse serum was dried onto a Formvar-coated grid. After rinsing with $0.1 \mathrm{M} \mathrm{PB}$ and incubation in GSDB, the grids were simultaneously treated with both secondary antibodies as described above. Examination of labeled grids showed virtually no cross-reactivity nor any aggregation of 5 and $10 \mathrm{~nm}$ gold particles.

\section{Results}

Differential distribution of synapsin I- and synapsin IIimmunoreactive puncta in the IPL

The IPL of the mammalian retina contains ribbon synapses made by bipolar cells and conventional synapses made by amacrine and interplexiform cells. We have previously demonstrated that synapsin I and II immunoreactivity is absent from ribbon synapses of bipolar cells (Mandell et al., 1990a). Thus, IPL synapsin immunoreactivity must arise from processes making conventional synapses. Since the vast majority of conventional synapses in the mammalian IPL are made by amacrine cells, we have attributed IPL synapsin immunostaining to synaptic terminals of amacrine cells.
Confocal scanning laser microscopy enabled high-resolution imaging of synapsin I or II immunofluorescence. Single confocal sections (effective thickness, $<0.5 \mu \mathrm{m}$ ) in the vertical plane revealed both synapsin I and II immunoreactivity as small puncta, confined to the IPL, ranging from 0.2 to $2 \mu \mathrm{m}$ in diameter. In order to visualize these structures in three dimensions, eight serial sections, encompassing an $\sim 4 \mu \mathrm{m}$ thickness of the IPL, were reconstructed (Fig. 1). Immunostaining for both synapsins I and II continued to appear as small, discrete, spherical structures; if staining were uniformly distributed throughout amacrine cell processes, three-dimensional reconstruction would have shown continuous varicose profiles instead of puncta. Thus, their size, shape, and restricted localization to the IPL suggest that these puncta represent the presynaptic boutons of conventional synapses. Although some puncta may represent a few closely apposed terminals unresolvable by light microscopy, many are probably single boutons.

The patterns of immunostaining for the $a$ and $b$ isoforms of synapsin I as well as those for the $\mathrm{a}$ and $\mathrm{b}$ isoforms of synapsin II were previously shown to be identical (Mandell et al., 1990a). In addition, both mono- and polyclonal antibodies recognizing one or more of the four synapsins gave corroborating results. With double-label confocal microscopy, we have seen no qualitative differences in the content of the $\mathrm{a}$ and $\mathrm{b}$ isoforms within single terminals (data not shown). Thus, we will refer simply to synapsin I or synapsin II without specifying the a or b isoform. The particular antibodies used and their isoform specificity are included in the figure captions. 

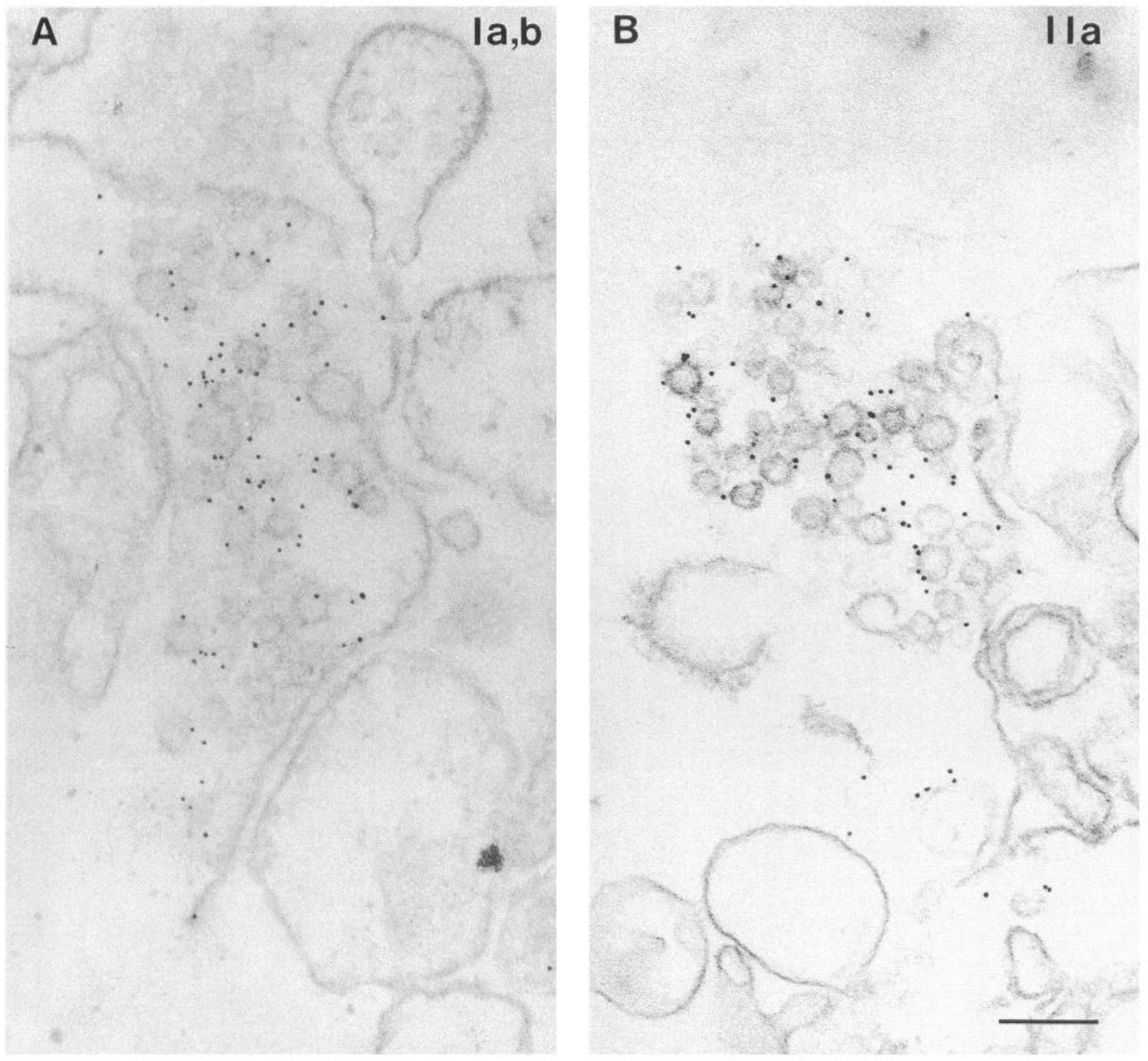

Figure 2. Immunoelectron microscopy of synapsin I and II labeling in lysed retinal synaptosomes. Synapsin I $(A)$ and synapsin II (B) immunoreactivity, indicated by $5 \mathrm{~nm}$ gold particles, is concentrated around small clear vesicles within profiles resembling conventional nerve terminals. Other membranes in the preparations are unlabeled. Antibodies used: synapsin I, I $(I a / b)$; synapsin II, G-281 (IIa). Secondary marker, protein A-gold (5 nm). Scale bar, $0.1 \mu \mathrm{m}$.

Synapsin I immunoreactive puncta were diffusely scattered across the thickness of the IPL (Fig. $1 A$ ). In contrast, the distribution of synapsin II-immunoreactive puncta was distinctly stratified, with a concentration in two narrow bands at $22-27 \%$ and $55-60 \%$ of the IPL width, and in a broad band from $70 \%$ to $100 \%$ (Fig. $1 B$ ). In addition, a few synapsin II-containing puncta were present in narrow bands at $5-10 \%$ and $40-45 \%$ of the IPL width. The stratified pattern of synapsin II immunostaining was similar in sections taken from both central and peripheral retina. Because the thickness of the IPL decreased toward the periphery, the spacing between synapsin II-containing strata was reduced.

Most previous studies of IPL stratification refer to a pentalaminar scheme in which the IPL is divided into five equal sublayers, each spanning $20 \%$ of its width. The stratification of synapsin II immunoreactivity itself clearly defined a subdivision of the IPL into five distinct, though not equal, sublayers. We have thus used a modified pentalaminar scheme in which sublayers $1-4$ each span $17 \%$ and sublayer $5,32 \%$ of the IPL width
(Fig. 1). We will refer to the division of the IPL into five portions as "sublayers" (S1-S5) and to observed patterns of immunoreactivity as "bands" or "strata" (Marc, 1986). In this scheme, the three major synapsin II-immunoreactive bands lie in S2, S4, and S5.

\section{Synapsin I and II immunoreactivity is restricted to small synaptic vesicles within conventional nerve terminals}

In order to confirm that synapsin immunoreactivity observed at the light microscopic level in the IPL originated from labeled synaptic vesicles within nerve terminals, electron microscopic immunolabeling was performed. The vast majority of immunolabeling for both synapsins I and II was localized to small synaptic vesicles (Fig. 2). Nonsynaptic membranes which served as internal controls in these experiments, were virtually unlabeled.

Synapsin I or II immunolabeling was found on clusters of vesicles within lysed nerve terminals. The appearance of these terminals was consistent with that of conventional synapses. In 


\section{Synapsin I}

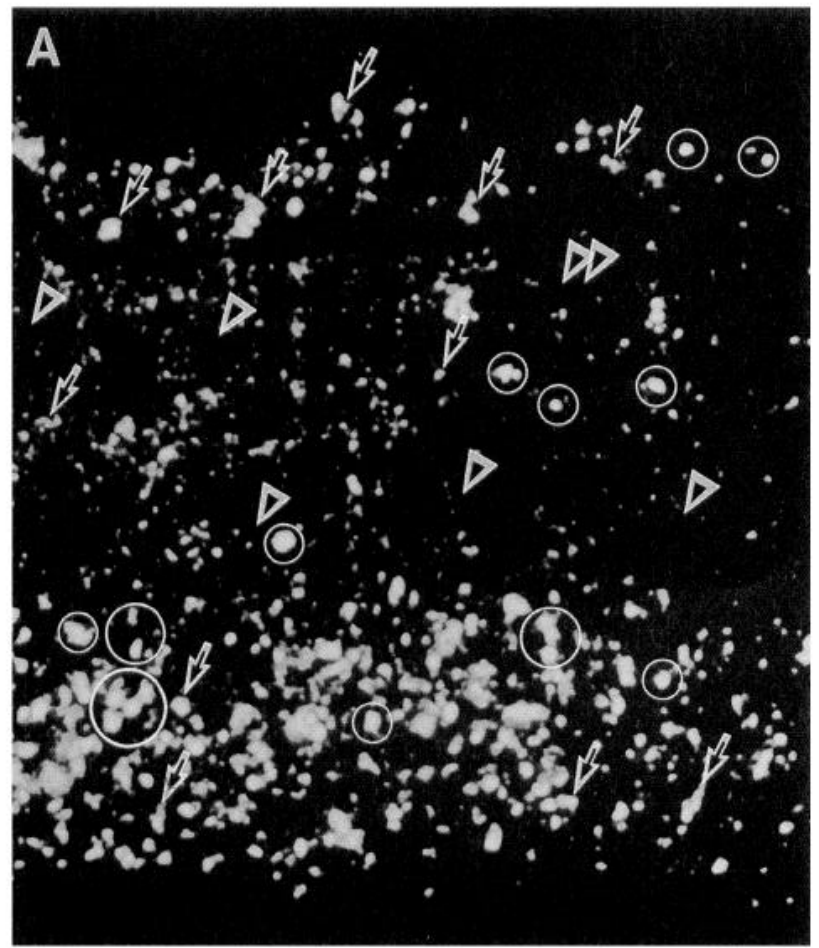

Synapsin II

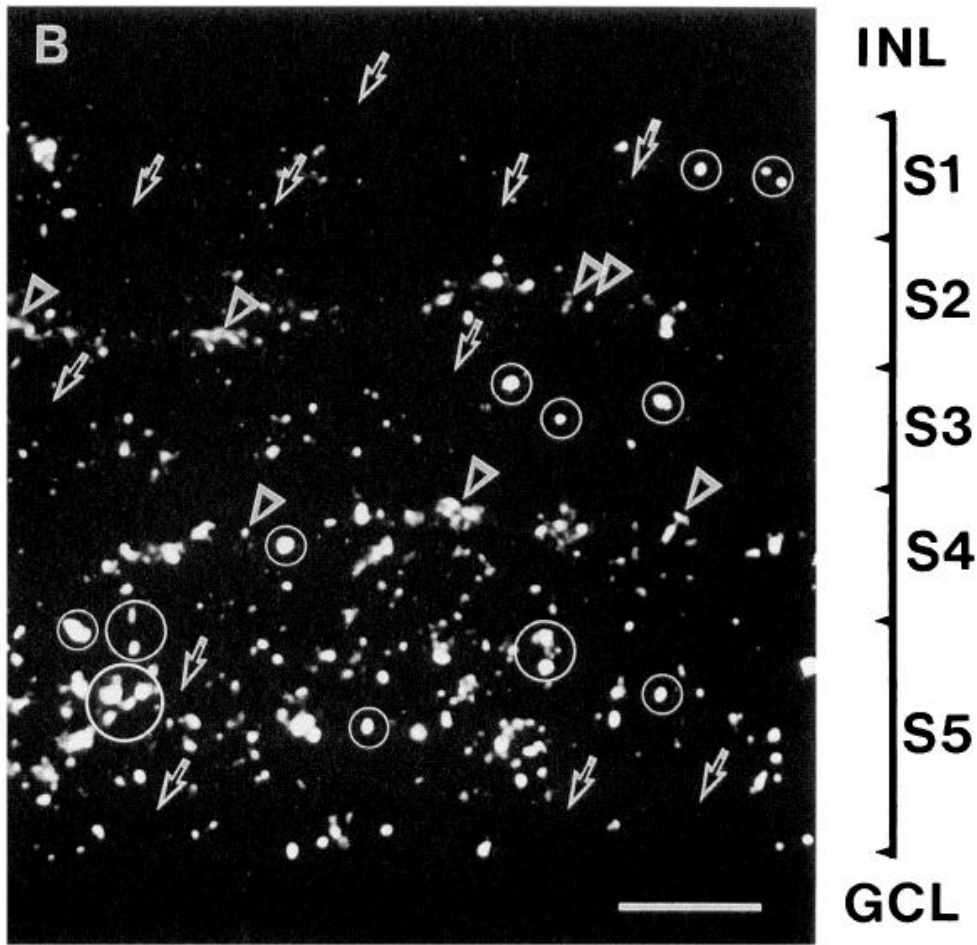

Figure 3. Double-label confocal microscopy reveals exclusive localization of synapsin I or synapsin II within some puncta and colocalization in others: synapsin I $(A)$ and synapsin II $(B)$ immunofluorescence imaged in a single optical section. Note that some puncta, especially in $S 1$, $S 3$, and $S 5$, contain exclusively synapsin I (arrows in $A$ ). Other puncta, especially in $S 2$ and $S 4$, contain exclusively synapsin II (arrowheads in $B$ ). A third population shows colocalization of synapsins I and II (circled in $A$ and $B$ ); these puncta are especially abundant within sublayer 5 . Antibodies used: synapsin I, mAb $10.22(I a / b)$ and Texas red; synapsin II, G-281 (IIa) and fluorescein. Scale bar, $10 \mu \mathrm{m}$.

some cases, a labeled presynaptic terminal was apposed to a postsynaptic membrane and a distinct synaptic cleft was visible (Fig. $2 A$ ). Some terminals, apparently not permeabilized by the lytic fixation procedure, were unlabeled (data not shown; see De Camilli et al., 1983b, for discussion of the technique). Immunoelectron microscopy supported our suggestion that puncta imaged by confocal microscopy represented labeled presynaptic terminals.

\section{Colocalization of synapsin I and synapsin II in some but not all nerve terminals}

Double-label confocal fluorescence microscopy revealed a feature of synapsin expression not seen with single-labeling techniques. At the level of individual puncta, the relative expression of the two synapsins varied dramatically (Fig. 3). Some puncta contained predominantly synapsin II and were devoid of synapsin I. These were found primarily in S2 and S4. Other puncta, especially in S1, S3, and S5, contained only synapsin I and little or no detectable synapsin II immunoreactivity. Yet others contained approximately equal quantities of the two synapsins. These were predominantly located in S5 and, to a lesser extent, S4. Thus, on the basis of their relative expression of the two synapsins, terminals within the IPL can be divided into three classes: synapsin $\mathrm{I}^{+} /$synapsin $\mathrm{II}^{-}$, synapsin $\mathrm{I}^{-} /$synapsin $\mathrm{II}^{+}$, and synapsin $\mathrm{I}^{+} /$synapsin $\mathrm{II}^{+}$. Of 325 puncta analyzed, $48 \%$ were synapsin $\mathrm{I}^{+} / \mathrm{II}^{-}, 24 \%$ were synapsin $\mathrm{I}^{-} / \mathrm{II}^{+}$, and $28 \%$ were synapsin $\mathrm{I}^{+} / \mathrm{II}^{+}$. The areal density (puncta/100 $\mu \mathrm{m}^{2}$ ) of all puncta was $\mathrm{S} 1,5.7$; S2, 9.4; S3, 7.8; S4, 10.7; and S5, 16.5. The density of the three classes of terminals was quantified within each of the five IPL sublayers (Fig. $4 A-C$ ). Synapsin $\mathrm{I}^{+} / \mathrm{II}^{-}$terminals were evenly distributed in S1-S4, with a greater density in S5, thus reflecting the overall density of terminals. Synapsin $\mathrm{I}^{-} / \mathrm{II}^{+}$terminals, in contrast, were heavily concentrated in S2 and S4. Synapsin $\mathrm{I}^{+}$/ $\mathrm{II}^{+}$terminals were found predominantly in S5, and to a lesser extent in S4.

The differential expression of the synapsins was also viewed in horizontal sections by means of confocal microscopy of double-immunolabeled retinal whole-mounts. Synapsin I and II immunoreactivity was imaged in three focal planes within the IPL (Fig. 5). For orientation, conventional immunofluorescence images of a vertical section, double labeled for synapsin I (Fig. $5 A$ ) and synapsin II (Fig. $5 H$ ), are shown. In horizontal sections through $\mathrm{S} 5$, near the ganglion cell layer (Fig. $5 F, G$ ), many puncta contained both synapsin I and II immunoreactivity. Horizontal sections through $\mathrm{S} 2$ and $\mathrm{S} 4$ (Fig. $5 B-E$ ) revealed many synapsin II-immunoreactive puncta that were devoid of synapsin I. The synapsin II-immunoreactive puncta in sublayers 2 and 4 were not randomly distributed but demonstrated clustering, giving rise to a discernable large-scale pattern. This was best observed in a reconstruction of three serial confocal sections within S2 (Fig. 6). Puncta could be seen to be arrayed in a netlike fashion, forming loops of various sizes around holes devoid of synapsin II immunoreactivity. The diameter of the loops ranged from about 10 to $25 \mu \mathrm{m}$.

In order to confirm that the heterogeneity observed at the light microscopic level represented variability in synapsin ex- 
pression within individual synaptic terminals, double-label immunoelectron microscopy was performed. We again performed immunogold labeling of agarose-embedded synaptosomes. Immunoreactivity for both synapsin I and II, visualized with 10 and $5 \mathrm{~nm}$ colloidal gold-conjugated secondary antibodies, respectively, was essentially restricted to small clear vesicles within conventional nerve terminals (Fig. 7). As predicted by doublelabel confocal microscopy, the relative expression of the two synapsins varied widely from terminal to terminal. Some contained predominantly synapsin I (Fig. $7 A$ ), others synapsin II (Fig. $7 C$ ), and still others both I and II (Fig. $7 B$ ). No obvious structural differences were observed between the three groups of terminals. Control preparations incubated with nonimmune rabbit serum and an irrelevant monoclonal antibody showed no significant labeling (Fig. $7 D$ ). The ratio of 10 to $5 \mathrm{~nm}$ gold particles (synapsin I and synapsin II, respectively) within 25 double-labeled terminals ranged from $22: 0$ to $4: 40$.

\section{Colocalization of synapsin II-containing terminals and CAT immunoreactivity}

The localization of many neurotransmitters and their synthesizing enzymes is highly stratified in the IPL of many vertebrate species (Karten and Brecha, 1983; Marc, 1986). This is largely due to the distinct laminar arborization patterns exhibited by amacrine cells of a given neurotransmitter phenotype. Thus, we sought to determine whether the stratification of terminals with distinct patterns of synapsin expression matched the localization of any known neurotransmitters. In virtually all vertebrate retinas, the processes of cholinergic amacrine cells stratify within $\mathrm{S} 2$ and $\mathrm{S} 4$. For this reason, we tested whether the synapsin $\mathrm{II}^{+} /$ synapsin $\mathrm{I}^{-}$terminals in $\mathrm{S} 2$ and $\mathrm{S} 4$ might belong to cholinergic amacrine cells.

CAT immunostaining of rat retina demonstrated, as previously described (Voigt, 1986), labeled amacrine somata in the inner nuclear and ganglion cell layer, as well as two narrow strata in the IPL. Double-labeling of sections with anti-CAT and synapsin II antibodies revealed exact colocalization of the two markers within S2 and S4 (Fig. 8). The pattern of bands and gaps in the CAT staining pattern was precisely reflected in the synapsin II immunostain. This discontinuous pattern of the cholinergic plexus seen in vertical sections is known to arise from the fasiculation of cholinergic processes (Tauchi and Masland, 1984). At the resolution provided by conventional immunofluorescence microscopy, however, it was not possible to discern whether the synapsin $\mathrm{II}^{+} /$synapsin $\mathrm{I}^{-}$terminals were identical to the CAT-positive terminals or were closely apposed.

\section{Noncolocalization of synapsin $I I$ and glutamic acid decarboxylase}

GAD, the synthetic enzyme for the inhibitory transmitter GABA, has been shown to have a stratified distribution in the rat IPL (Vaughn et al., 1981; Brandon, 1985). GAD-immunoreactive terminals are found throughout most of the IPL except within two narrow strata in sublayers 2 and 4 . Interestingly, the positions of the two narrow GAD-negative strata were close to that of synapsin II-rich terminals. We examined this apparent negative relationship via double-label immunofluorescence with anti-GAD serum and anti-synapsin II antibodies (Fig. 9). The GAD antiserum gave intense, somewhat punctate labeling in discrete strata within the IPL and less intense staining of a subset of INL somata. Conventional double-label immunofluorescence showed that the synapsin II-immunoreactive strata in S2 and
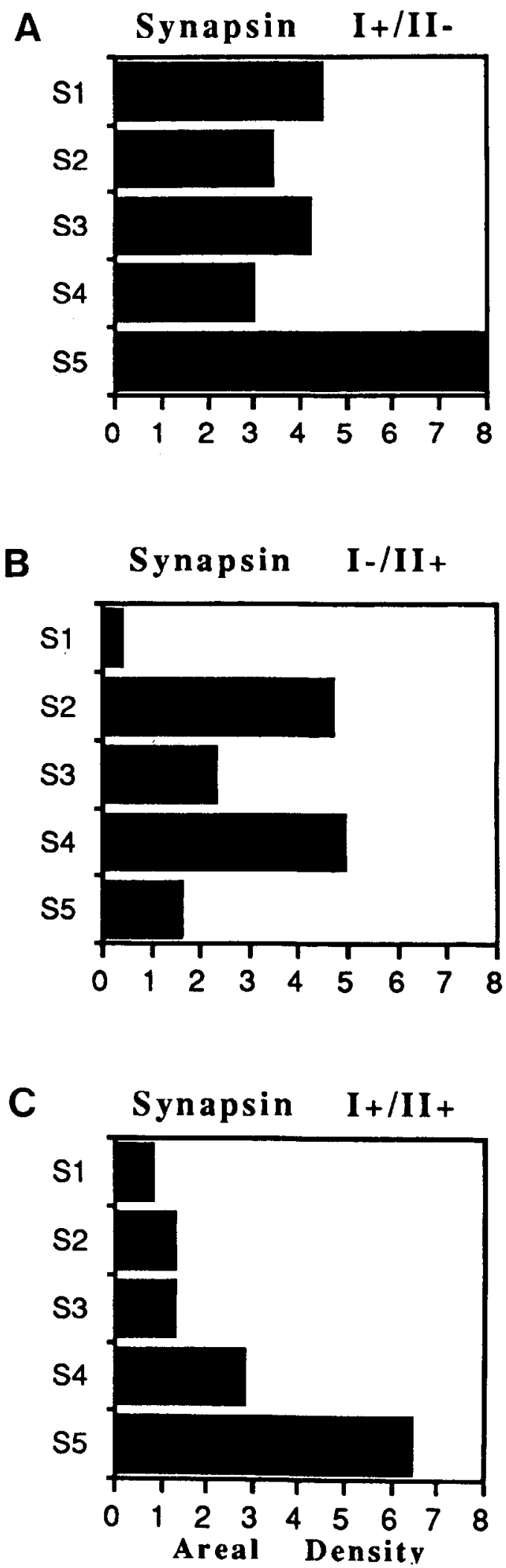

Figure 4. Quantitative distribution of synapsin I- and II-immunoreactive terminals within IPL sublayers. Double-label confocal microscopy was used to image synapsin I and II immunofluorescence. Individual puncta were classified as synapsin $\mathrm{I}^{+} / \mathrm{II}^{-}(A)$, synapsin $\mathrm{I}^{-} / \mathrm{II}^{+}(B)$, or synapsin $\mathrm{I}^{+} / \mathrm{II}^{+}(C)$. The areal density (puncta/100 $\left.\mu \mathrm{m}^{2}\right)$ of each class of puncta is plotted for each sublayer, $S I-S 5$. 


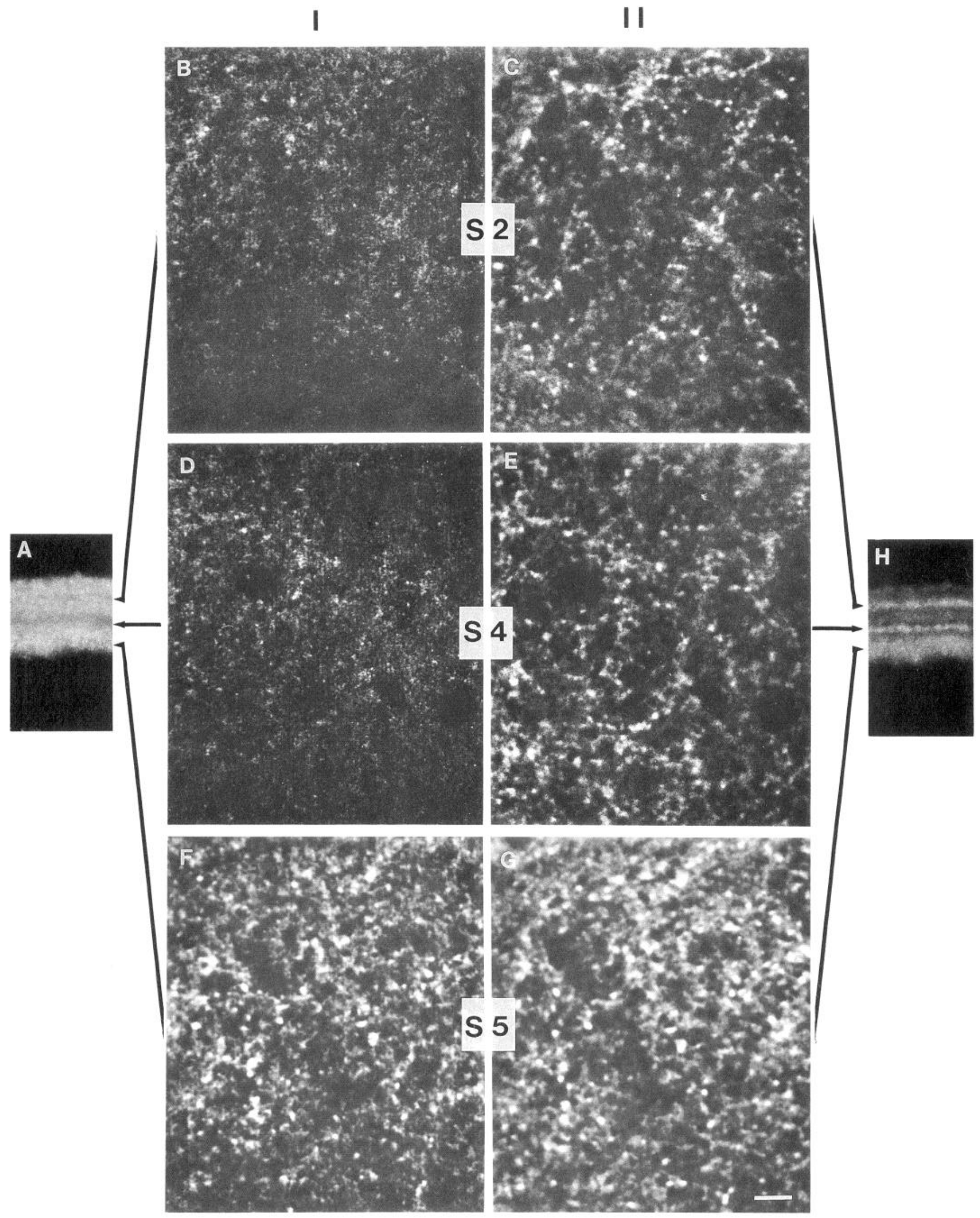

Figure 5. Double-label imaging of synapsin I and II immunoreactivity in horizontal confocal sections through the IPL. Conventional immunofluorescence of synapsin I $(A)$ or synapsin II $(H)$ is shown in vertical sections to indicate the approximate depth within the IPL at which the horizontal sections were taken. Single horizontal confocal sections within $S 2$ and $S 4$ reveal many synapsin II-immunoreactive puncta $(C, E)$ that are devoid of synapsin I $(B, D)$. In contrast, most puncta within $S 5$ are immunoreactive for both synapsins I $(F)$ and II $(G)$. Note that synapsin II-containing puncta in $S 2$ and $S 4$ are nonrandomly arranged in a netlike pattern. Antibodies used: synapsin I, mAb 10.22 (Ia/b) and rhodamine; synapsin II, G-281 (IIa) and fluorescein. Scale bar, $10 \mu \mathrm{m}$. 

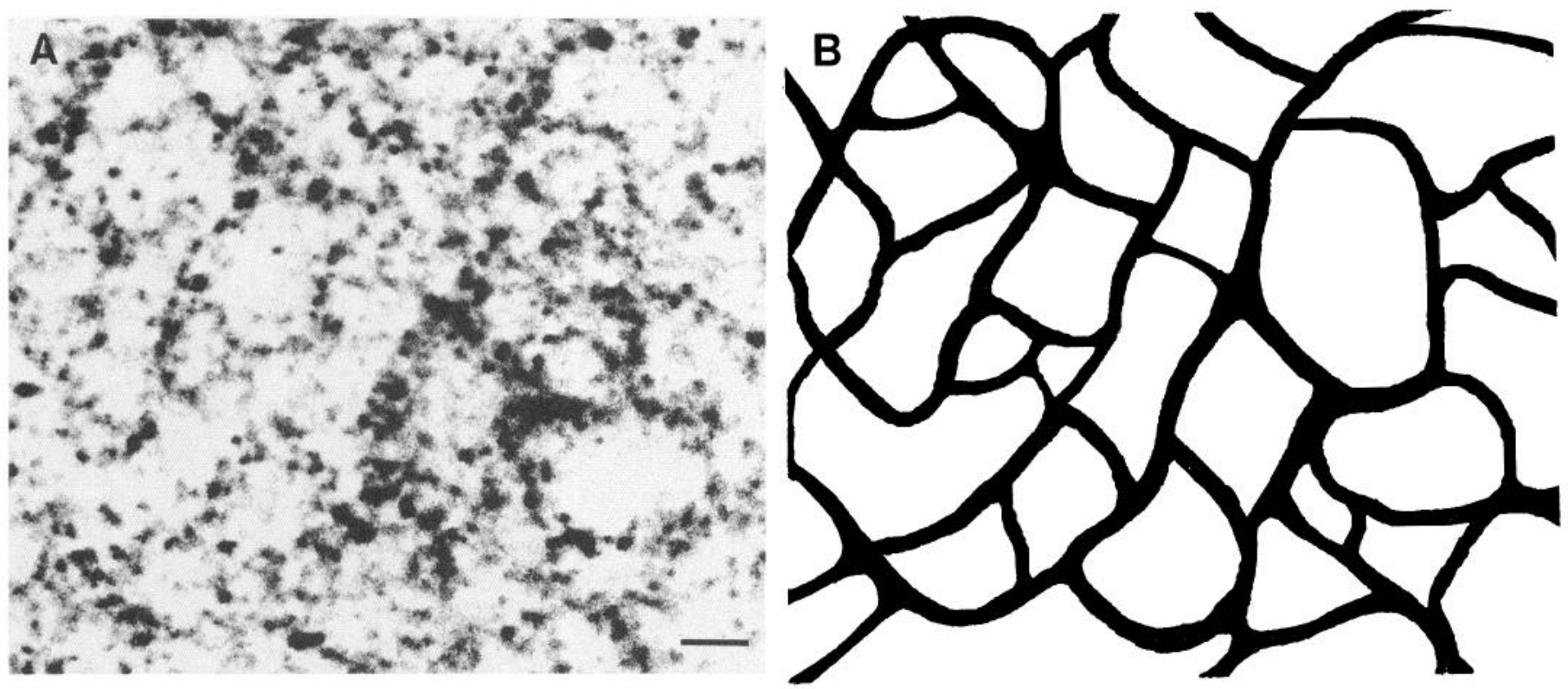

Figure 6. Reconstruction of serial confocal sections revealing plexus of synapsin II-immunoreactive puncta. Synapsin II immunofluorescence was viewed in a whole-mount preparation by reconstructing serial optical sections within $\mathrm{S} 2(A)$. Immunofluorescence is shown in negative image. Immunoreactive puncta are arranged in a meshlike plexus, forming loops around zones devoid of synapsin II immunolabeling. The most prominent loops are shown in schematic form $(B)$. They range from 10 to $30 \mu \mathrm{m}$ in diameter. Antibody used, G-281 (IIa). Scale bar, $10 \mu \mathrm{m}$.

S4 corresponded precisely to the GAD-negative sublayers (Fig. $9 A, B)$. Furthermore, with confocal microscopy, it could be seen that synapsin II-immunoreactive puncta in S5 as well as S2 and S4 were devoid of GAD immunoreactivity. Conversely, all GADpositive puncta were devoid of synapsin II immunoreactivity (Fig. 9C,D). Thus, it appears that synapsin II- and GAD-immunoreactive puncta represent distinct and nonoverlapping populations of nerve terminals.

\section{Discussion}

Our results provide evidence for a large degree of molecular heterogeneity among presynaptic terminals. We have shown that conventional retinal synapses differ greatly in their relative expression of two closely related SVPs, synapsins I and II. Our observations suggest a division of these synapses into three classes: those containing predominantly synapsin I, synapsin II, or both. This classification is given significance by our finding that each class shows a distinct distribution pattern within the five IPL sublayers. Furthermore, one such class, those containing only synapsin II, may consist largely of synapses of cholinergic amacrine cells. In addition, these and other terminals containing high levels of synapsin II are distinct from GAD-immunoreactive terminals (Fig. 10).

\section{Differential expression of synapsins I and II within individual nerve terminals}

Previous biochemical studies showed that synapsins I and II were grossly colocalized in all brain regions studied (Browning et al., 1987; Walaas et al., 1988). Immunocytochemistry, by allowing detection of proteins in single cells, has begun to provide evidence of differential expression of the synapsins (Südhof et al., 1989; Mandell et al., 1990a). Using both confocal and electron microscopy, we have provided the first indication that conventional nerve terminals may express only synapsin I (a and $b$ ) or only synapsin II (a and b). Unlike the dramatic variations seen upon comparison of synapsins I and II, no quali- tative differences were noted between expression of the $a$ and $b$ isoforms of synapsin I or between the $\mathrm{a}$ and $\mathrm{b}$ isoforms of synapsin II. Because immunocytochemistry cannot rule out the presence of very low levels of antigen, it is possible that all terminals do contain all four synapsins. However, there clearly is wide variation in the relative levels of synapsin I and synapsin II immunoreactivity among individual terminals. Our findings are strengthened by the fact that a number of different monoand polyclonal antibodies to the synapsins gave corroborating results. We did not directly address the possibility that some conventional synapses might lack all synapsin isoforms.

\section{Relationship of synapsin II-rich terminals to cholinergic and GABAergic amacrine cells}

Retinal amacrine cells classified by their neurotransmitter phenotype are known to exhibit stereotyped patterns of process stratification. Because synapsin $\mathrm{II}^{+} /$synapsin $\mathrm{I}^{-}$puncta were concentrated within two strata, we attempted to correlate this pattern with that of known neurotransmitters. We demonstrated by immunofluorescence that synapsin $\mathrm{II}^{+} /$synapsin $\mathrm{I}^{-}$puncta in $\mathrm{S} 2$ and S4 colocalize with processes of CAT-positive cholinergic amacrine cells. Further evidence for the cholinergic identity of the synapsin $\mathrm{II}^{+} /$synapsin $\mathrm{I}^{-}$puncta is provided by the fact that the meshlike network formed by these puncta as seen in horizontal sections through $\mathbf{S} 2$ and S4 is strikingly similar in scale and appearance to the cholinergic plexus as seen by CAT immunocytochemistry (Voigt, 1986; Brandon, 1987; Famiglietti and Tumosa, 1987) or by Lucifer yellow injection of neighboring cholinergic amacrine cells (Tauchi and Masland, 1984).

It would be of interest to know if the exclusive expression of synapsin II by presumptive cholinergic amacrine cells is related to known structural or functional features of these neurons. Ultrastructural analysis of immunoperoxidase-labeled retinal cholinergic synapses in rabbit, chicken, and monkey showed them to be similar in appearance to other amacrine cell synapses (Brandon, 1987; Millar et al., 1987; Mariani and Hersh, 1988). 

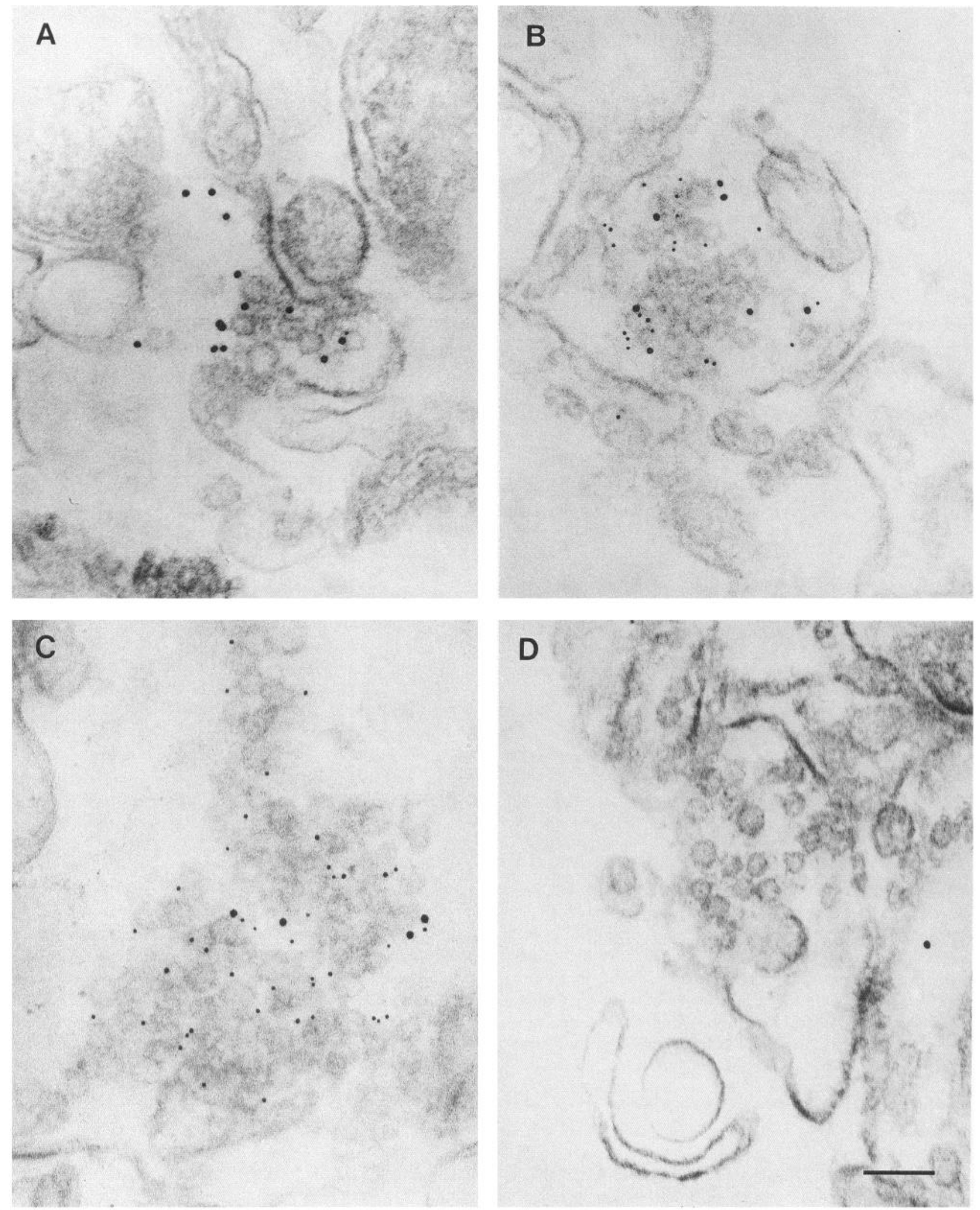

Figure 7. Double-label immunoelectron microscopy of lysed retinal synaptosomes. Some synaptosomes contain predominantly synapsin I (large gold particles; $A$ ). Others contain both synapsin I and II (small gold particles; $B$ ). Yet others contain predominantly synapsin II (C). As a control, normal rabbit serum and an irrelevant monoclonal antibody (Sal-1) were substituted for the synapsin antibodies $(D)$. No significant labeling was observed. Antibodies used: synapsin I, $\mathrm{I}_{4}(\mathrm{Ia} / \mathrm{b})$; synapsin II, mAbs 19.31 and 19.41 (IIa/b). Scale bar, $0.1 \mu \mathrm{m}$. 

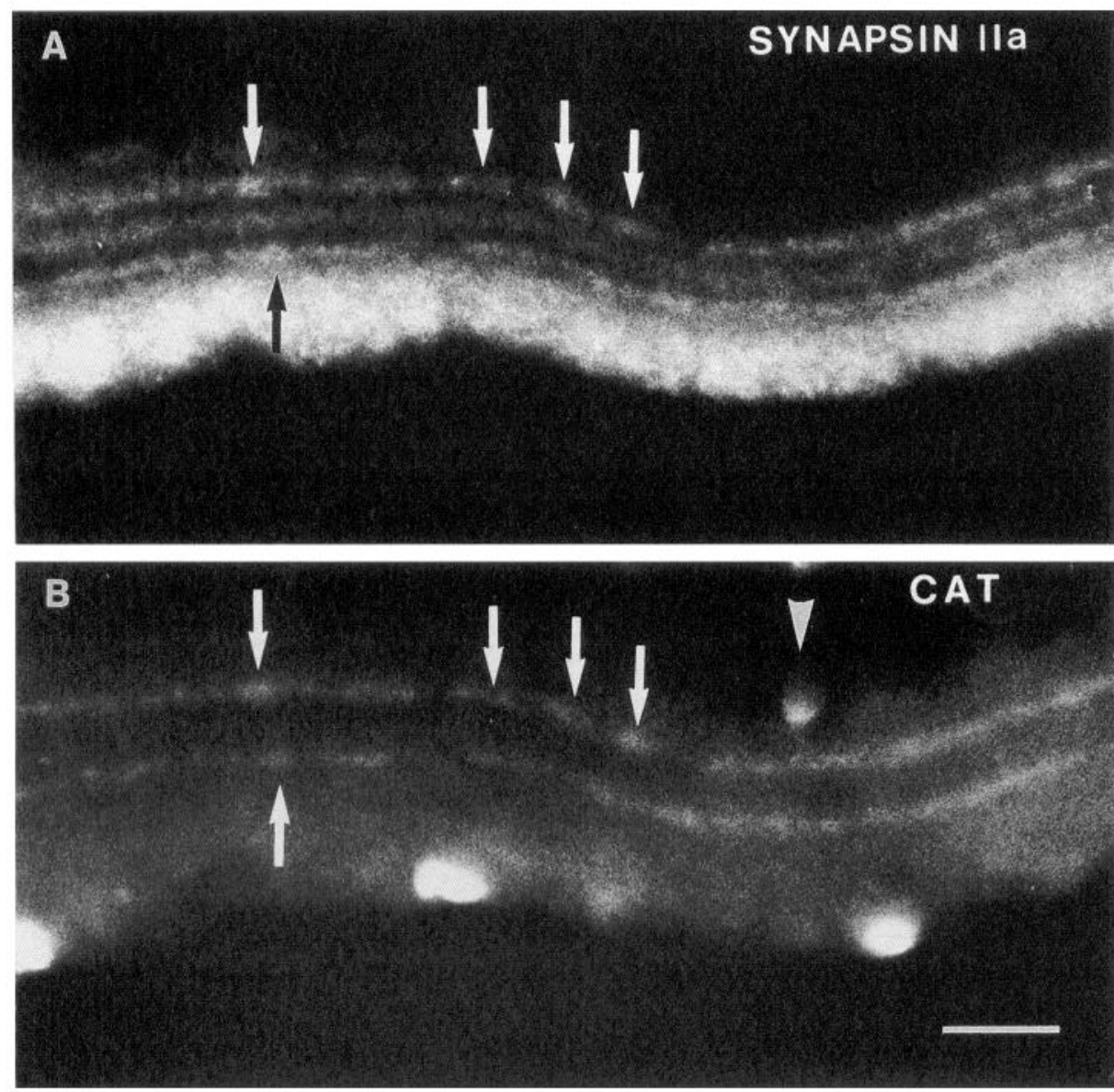

Figure 8. Double-label immunofluorescence localization of synapsin II and CAT. Synapsin II immunolabeling $(A)$ is restricted to the IPL and is concentrated in S2, S4, and S5. CAT immunoreactivity $(B)$ is seen in two narrow strata and in a cell body in the INL (arrowhead in B). Synapsin II immunolabeling within $\mathrm{S} 2$ and $\mathrm{S} 4$ coincides exactly with the two CAT-immunoreactive strata. Note that the pattern of bands and gaps for both markers are identical within these sublayers (arrows in $A$ and $B$ ). The large bright spots in $B$ are nonspecifically stained blood vessels near the ganglion cell layer. Antibodies used: synapsin II, G-281 (IIa) and rhodamine; CAT, monoclonal rat anti-CAT (Boehringer Mannheim) and fluorescein. Scale bar, $25 \mu \mathrm{m}$.
The only remarkable ultrastructural feature noted was the absence of any dense-core vesicles in the cholinergic processes (Millar et al., 1987).

The physiology of cholinergic amacrine cells has been intensely studied because these neurons have been implicated in the detection of visual motion (Masland et al., 1984). A number of authors have suggested that synaptic varicosities of these cells may process information locally (i.e., without communication to the soma) since they receive synaptic input within microns of their presynaptic active zones. Since the varicosities are thought to be electrically isolated from each other (Miller and Bloomfield, 1983), they would release transmitter only in response to local synaptic input. Furthermore, in the rabbit retina, $\mathrm{ACh}$, an excitatory transmitter, is colocalized and coreleased with an inhibitory transmitter, GABA (Brecha et al., 1988; Vaney and Young, 1988; O'Malley and Masland, 1989). It is possible that corelease (and possibly differential release) of these two transmitters in response to local synaptic input requires a specialized regulatory mechanism. Our finding that presumptive cholinergic terminals have an unusual pattern of synapsin expression (i.e., synapsin II without synapsin I) may be related to such a specialized mechanism.

It should be emphasized that synapsin isoform expression may not be directly related to neurotransmitter phenotype per se, but might reflect a physiological (as opposed to neurochemical) parameter of neurotransmitter release. For example, our findings suggest that cholinergic amacrine cell presynaptic terminals contain synapsin II but are devoid of detectable synapsin
I. Cholinergic motor neuron terminals, however, contain abundant synapsin I (Valtorta et al., 1988). Thus, synapsin isoform expression is not simply related to neurotransmitter phenotype.

We demonstrated by immunofluorescence that the synapsin II-rich, CAT-positive terminals in sublayers 2 and 4 lacked detectable GAD, the GABA synthetic enzyme. It is known, however, that GAD immunocytochemistry shows consistent discrepancies with patterns of GABA uptake and GABA immunocytochemistry (Mosinger and Yazulla, 1985, 1987). Thus, there may be GABAergic terminals that do not express detectable levels of GAD. A previous study revealed that CAT-positive amacrine cell bodies in rat retina, while almost always GABA-positive, were weakly reactive or nonreactive for GAD (Kosaka et al., 1988). Furthermore, GABA immunocytochemistry of the rat IPL showed uniform staining across all sublayers, suggesting that the narrow GAD-negative strata are GABA positive (J. W. Mandell, unpublished observations). Thus, in spite of their lack of GAD immunoreactivity, it is still possible that the synapsin $\mathrm{II}^{+} /$synapsin $\mathrm{I}^{-} / \mathrm{CAT}$-positive terminals in question are GABAergic, as is thought to be the case for cholinergic amacrine cells in rabbit.

\section{Relationship to synapse classification systems}

The division of brain chemical synapses into two major classes, Gray's type I and type II (Gray, 1959), based on the appearance of synaptic vesicles and synaptic densities, has proven to be a useful if incomplete scheme. Among conventional synapses in the mammalian retina, however, no such clear distinction exists. 

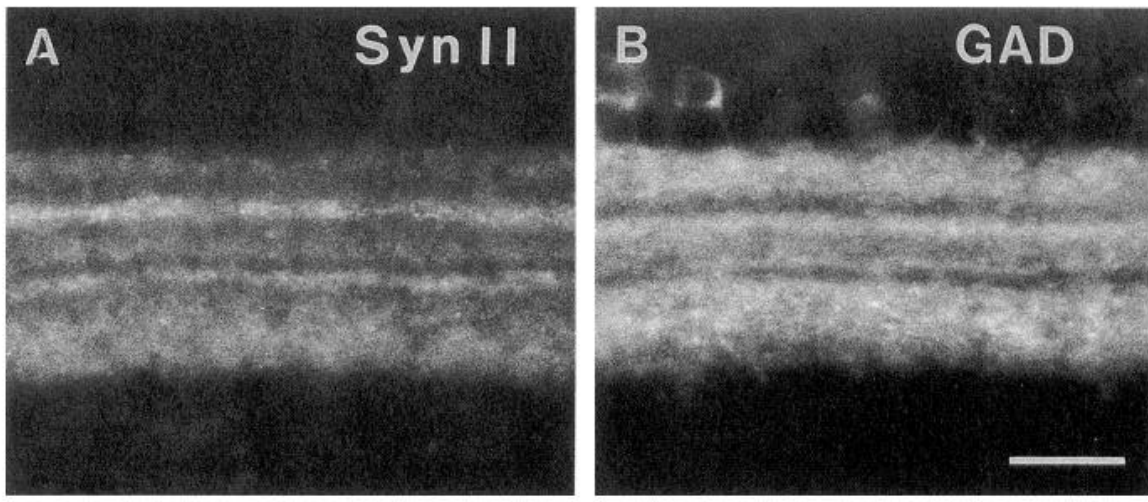

Figure 9. Noncolocalization of synapsin II and GAD immunoreactivity. Double-label conventional immunofluorescence reveals a complementary relationship between synapsin II $(A)$ and GAD $(B)$ immunoreactivity in S1-S4. The two brightly immunoreactive synapsin II strata in S2 and S4 correspond precisely to the narrow GAD-negative strata. Double-label confocal immunofluorescence demonstrates that puncta immunoreactive for synapsin II $(C)$ and GAD $(D)$ are mutually exclusive in all IPL sublayers. Examples of puncta containing synapsin II immunoreactivity but no GAD immunoreactivity are shown (circled in $C$ ). Examples of puncta containing GAD immunoreactivity but no synapsin II are indicated (arrowheads in $D$ ). Antibodies used: synapsin II, G-281 (IIa) and fluorescein; GAD, human antiGAD and Texas red. Scale bars: $A$ and $B, 25 \mu \mathrm{m} ; C$ and $D, 10 \mu \mathrm{m}$.
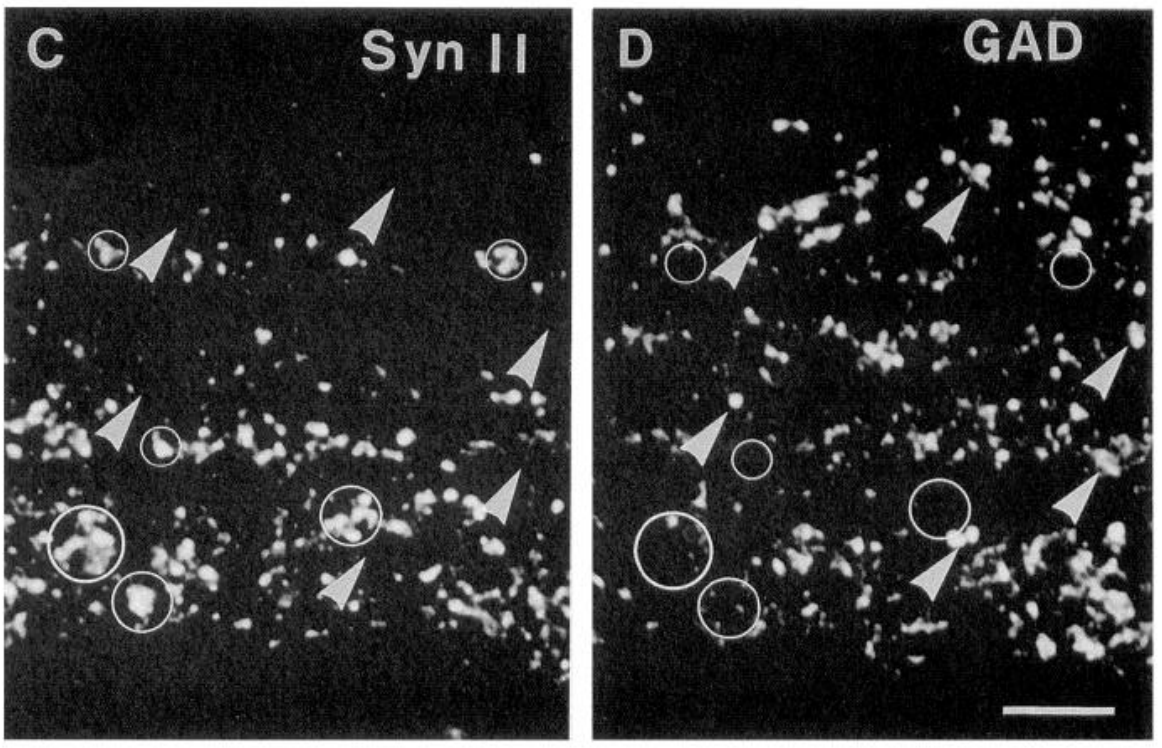

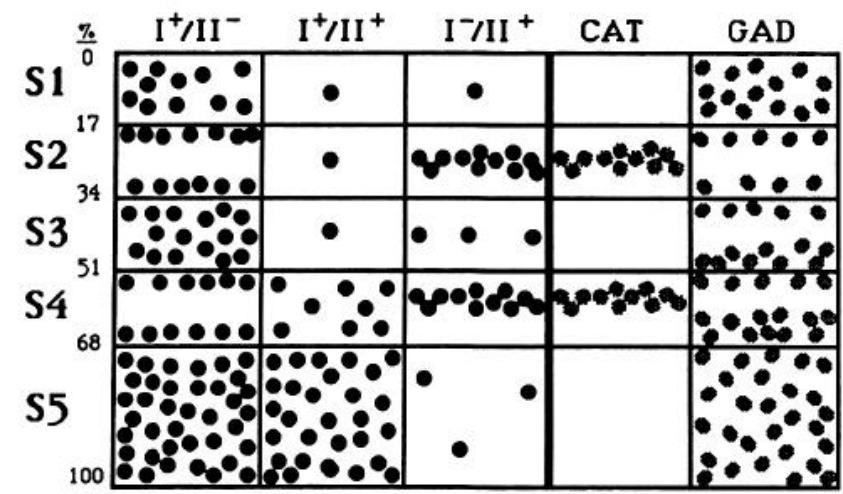

Figure 10. Schematic summary of synapsin localization patterns within the retinal IPL. The distribution among sublayers $S 1-S 5$ of synaptic terminals containing only synapsin $\mathrm{I}\left(\mathrm{I}^{+} / I I^{-}\right)$, both synapsins I and II $\left(I^{+} / I I^{+}\right)$, or only synapsin II $\left(I^{-} / I I^{+}\right)$is indicated by dots. Whereas $I^{+} /$ $I^{-}$terminals are fairly evenly distributed, $\mathrm{I}^{+} / \mathrm{II}^{+}$terminals are almost exclusively found in $S 4$ and $S 5 . I^{-} / I I^{+}$terminals are heavily concentrated in $S 2$ and $S 4$, exactly at the positions where CAT-positive processes of cholinergic amacrine cells stratify. GAD-positive terminals of GABAergic amacrine cells are found throughout most of the IPL, except in two narrow strata within $S 2$ and $S 4$. They are all synapsin II $^{-}$and are distinct from the synapsin $\mathrm{I}^{-} / \mathrm{II}^{+}$, CAT-positive terminals.
Amacrine cell synapses do not exhibit the marked asymmetric membrane densities characteristic of type I synapses, nor do they contain discrete populations of round and flattened vesicles. However, a freeze-fracture study of the IPL revealed three classes of conventional synapses based on the distribution of postsynaptic intramembranous particles (Raviola and Raviola, 1982). The vast majority had the appearance of inhibitory (type II) synapses. These were further subdivided based on the presence or absence of intramembranous (P-face) particles. Finally, synapses reminiscent of excitatory (type I) junctions, with dense focal aggregates of intramembranous (E-face) particles, were only rarely seen. Our immunoelectron microscopic analysis did not indicate whether differences in synapsin expression might be correlated with such structural features. Structural variation, if it did exist, would be obscured by the destructive nature of the lytic immunoelectron microscopic technique used. Possible structural correlates of heterogeneity in nerve terminal synapsin content may be revealed by combining high-resolution EM techniques such as rapid freeze-deep etching, freeze-fracture, and freeze-substitution, with synapsin immunolabeling.

The most fundamental classification of synapses is the functional division into excitatory and inhibitory junctions. Our results suggest that excitatory cholinergic synapses in the rat retina, unlike most other IPL terminals, contain exclusively 
synapsin II. A recent report has identified another type of synaptic terminal, that of olfactory receptor neurons, with a high synapsin II:I ratio (Finger and Browning, 1990). Although its neurotransmitter is unknown, its ultrastructural appearance is that of a type I, excitatory synapse. Thus, a high level of synapsin II expression relative to synapsin I may be associated with excitatory synapses. In addition, we have shown that GAD-positive terminals in the retina lack synapsin II. Terminals of cerebellar Purkinje cells, which are also GAD positive and known to be inhibitory, were similarly shown to lack synapsin IIa and express low levels of synapsin IIb (Südhof et al., 1989). Clearly, however, many more identified synapse types must be examined before strong correlations can be drawn.

\section{Relationship to IPL circuitry}

The laminar distribution of terminals with similar patterns of synapsin expression may correlate with known morphological and functional stratification of the IPL. We demonstrated that terminals containing only synapsin I did not show preferential localization to any particular sublaminae. Those with only synapsin II were concentrated within sublaminae 2 and 4 , whereas terminals with both synapsins were concentrated in sublamina 5. Quantitative EM analyses of the vertebrate IPL have revealed significant stratification among synapse types (Dubin, 1970; West, 1976; Koontz and Hendrickson, 1987). Of particular interest are studies in the primate retina, which demonstrated distinct stratification patterns for amacrine synapses onto bipolar cells, ganglion cells, and other amacrine cells (Koontz and Hendrickson, 1987). Each of thesc threc amacrinc synapse types might have different functional requirements and, possibly, differences in synapsin content. The existence of significant interspecies variations in the pattern of IPL stratification, however, restricts a direct comparison with our findings in rat retina.

As in other vertebrates (Ramón y Cajal, 1892), arbors of retinal amacrine cells in the rat exhibit two basic morphologies: stratified and diffuse (i.e., having no stratification). The fact that the pattern of all synapsin II-containing terminals is highly stratified suggests that they are contributed only by stratified cells and that the terminals of diffuse cells are devoid of synapsin II. Similarly, the relatively diffuse pattern of synapsin I-immunoreactive puncta suggests that at least some of them are contributed by diffuse amacrine cells. Terminals containing both synapsins, which were found almost exclusively in S5 and, to a lesser extent, $\mathbf{S} 4$, could be contributed by one class of amacrine cell (stratificd-diffuse), which arborizes in just these two sublayers (Perry and Walker, 1980). However, these suggestions are contingent upon an extension of Dale's Principle to SVPs. That is, they rely on the hypothesis that every branch of a single neuron expresses an identical array of synapsin molecules. It is possible, and we have no evidence either for or against the idea, that a single amacrine cell could contain different levels of the four synapsins in its various terminals.

The primary functional division of the IPL is into OFF and ON sublaminae (a and $b$, each comprising roughly half of the IPL nearest the inner nuclear layer and ganglion cell layer, respectively; Famiglietti and Kolb, 1976). Amacrine cells that hyperpolarize in response to light make synapses primarily in sublamina a (OFF), and cells that depolarize do so in sublamina b $(O N)$. Of the three classes of synapses defined by synapsin expression, only one respects the ON/OFF division. These are the synapsin $\mathrm{I}^{+} / \mathrm{II}^{+}$terminals, $81 \%$ of which were found in the ON sublayer.

\section{Possible physiological significance}

Because synapsins I and II are among the most abundant nerve terminal proteins, and in light of strong evidence for a role for synapsin $I$ in the regulation of vesicular transmitter release, we believe that the observed variations in synapsin content have functional significance. The finding that nerve terminals may contain only one of the two synapsins raises the possibility that the presence of both is not an absolute requirement for presynaptic function. The four synapsins contain homologous as well as unique domains in their primary sequence, suggesting that they share some but not all functional properties (Südhof et al., 1989). The common domains contain the site that is phosphorylated by cAMP-dependent protein kinase and $\mathrm{Ca}^{2+} / \mathrm{calmo-}$ dulin-dependent protein kinase $\mathrm{I}$, as well as the proposed actinbinding domains and a hydrophobic region thought to interact with the vesicle phospholipid bilayer. Synapsin II, like synapsin I, contains a domain capable of binding to synaptic vesicles in vitro (Thiel et al., 1990). The most prominent molecular difference between the synapsin I and synapsin II isoforms is the presence in synapsin I of a proline-rich, basic tail region that contains two sites phosphorylated by $\mathrm{Ca}^{2+} / \mathrm{calmodulin}$-dependent protein kinase II. These sites are absent from synapsin II. Thus, the relative expression of synapsins I and II within nerve terminals, in conjunction with the relative activities of the various kinases and phosphatases, might be a determinant of the $\mathrm{Ca}^{2+}$ sensitivity of transmitter release. This idea might be tested by simultaneously monitoring intraterminal $\mathrm{Ca}^{2+}$ concentration and presynaptic transmitter release at synaptic terminals with known synapsin isoform content.

\section{References}

Bahler M, Greengard P (1987) Synapsin I bundles F-actin in a phosphorylation-dependent manner. Nature 326:704-707.

Baumert M, Maycox PR, Navone F, De Camilli P, Jahn R (1989) Synaptobrevin: an integral membrane protein of 18,000 daltons present in small synaptic vesicles of rat brain. EMBO J 8:379-384.

Baumert M, Takei K, Hartinger J, Burger PM, Fischer VMG, Maycox PR, De Camilli P, Jahn R (1990) P29: a novel tyrosine-phosphorylated membrane protein present in small clear vesicles of neurons and endocrine cells. J Cell Biol 110:1285-1294.

Brandon C (1985) Retinal GABA neurons: localization in vertebrate species using an antiserum to rabbit brain glutamate decarboxylase. Brain Res 344:286-295.

Brandon C (1987) Cholinergic neurons in the rabbit retina: dendritic branching and ultrastructural connectivity. Brain Res 426:1 19-130.

Brecha N, Johnson D, Peichl L, Wassle H (1988) Cholinergic amacrine cells of the rabbit retina contain glutamate decarboxylase and gammaaminobutyrate immunoreactivity. Proc Natl Acad Sci USA 85:61876191.

Browning MD, Huang CK, Greengard P (1987) Similarities between protein IIIa and protein IIIb, two prominent synaptic vesicle-associated phosphoproteins. J Neurosci 7:847-853.

Buckley K, Kelly RB (1985) Identification of a transmembrane glycoprotein specific for secretory vesicles of neural and endocrine cells. J Cell Biol 100:1284-1294.

De Camilli P, Jahn R (1990) Pathways to regulated exocytosis in neurons. Annu Rev Physiol 52:625-645.

De Camilli P, Cameron R, Greengard P (1983a) Synapsin I (protein I), a nerve terminal-specific phosphoprotein. I. Its general distribution in synapses of the central and peripheral nervous system demonstrated by immunofluorescence in frozen and plastic sections. J Cell Biol 96:1337-1354.

De Camilli P, Harris SM, Huttner WB, Greengard P (1983b) Synapsin I (protein I), a nerve terminal-specific phosphoprotein. II. Its specific association with synaptic vesicles demonstrated by immunocytochemistry in agarose-embedded synaptosomes. J Cell Biol 96:13551373. 
Dubin MW (1970) The inner plexiform layer of the vertebrate retina: a quantitative and comparative electron microscopic analysis. J Comp Neurol 140:479-506.

Elferink LA, Trimble WS, Scheller RH (1989) Two vesicle-associated membrane protein genes are differentially expressed in the rat central nervous system. J Biol Chem 264:11061-1 1064

Famiglietti EV, Kolb H (1976) Structural basis for ON- and OFFresponses in retinal ganglion cells. Science 194:193-195.

Famiglietti EV, Tumosa N (1987) Immunocytochemical staining of cholinergic amacrine cells in rabbit retina. Brain Res 413:398-403.

Finger TE, Browning MD (1990) High levels of synapsin II in olfactory bulb. Soc Neurosci Abstr 16:499.

Gray EG (1959) Axosomatic and axodendritic synapses of the cerebral cortex: an electron microscope study. J Anat 93:420-433.

Gray EG (1969) Electron microscopy of excitatory and inhibitory synapses: a brief review. Prog Brain Res 31:141-155.

Gulley RL, Landis DM, Reese TS (1978) Internal organization of membranes at end bulbs of Held in the anteroventral cochlear nucleus. J Comp Neurol 180:707-741.

Hackett JT, Cochran SL, Greenfield LJ, Brosius DC, Ueda T (1990) Synapsin I injected presynaptically into goldfish mauthner axons reduces quantal synaptic transmission. J Neurophys 63:701-706.

Hirokawa N, Sobue K, Kanda K, Harada A, Yorifuji H (1989) The cytoskeletal architecture of the presynaptic terminal and molecular structure of synapsin I. J Cell Biol 108:111-126.

Jahn R, Schiebler W, Ouimet C, Greengard P (1985) A 38,000-dalton membranc protcin (p38) present in synaptic vesicles. Proc Natl Acad Sci USA 82:4137-4141.

Johnson GD, Davidson R, McNamee K, Russell G, Goodwin D, Holoborow EJ (1982) Fading of immunofluorescence during microscopy: a study of the phenomenon and its remedy. J Immunol Methods 55:231-242.

Karten HJ, Brecha N (1983) Localization of neuroactive substances in the vertebrate retina: evidence for lamination in the inner plexiform layer. Vision Res 23:1197-1205.

Koontz MA, Hendrickson AE (1987) Stratified distribution of synapses in the inner plexiform layer of primate retina. J Comp Neurol 263:581-592.

Kosaka T, Tauchi M, Dahl JL (1988) Cholinergic neurons containing GABA-like and/or glutamic acid decarboxylase-like immunoreactivities in various brain regions of the rat. Exp Brain Res 70:605-617.

Landis DM, Hall AK, Weinstein LA, Reese TS (1988) The organization of cytoplasm at the presynaptic active zone of a central nervous system synapse. Neuron 1:201-209.

Lin JW, Sugimori M, Llinás RR, McGuinness T, Greengard P (1990) Effects of synapsin I and calcium/calmodulin-dependent protein kinase II on spontaneous neurotransmitter release in the squid giant synapse. Proc Natl Acad Sci USA 87:8257-8261.

Llinás R, McGuinness TL, Leonard CS, Sugimori M, Greengard P (1985) Intraterminal injection of synapsin I or calcium/calmodulindependent protein kinase II alters neurotransmitter release at the squid giant synapse. Proc Natl Acad Sci USA 82:3035-3039.

Mandell JW, Townes-Anderson E, Czernik AJ, Cameron R, Greengard P, De Camilli P (1990a) Synapsins in the vertebrate retina: absence from ribbon synapses and heterogeneous distribution among conventional synapses. Neuron 5:19-33.

Mandell JW, Czernik AJ, DeCamilli P, Townes-Anderson E (1990b) Laminar distribution of the synapsins in the inner plexiform layer of the rat retina. Invest Ophth Vis Sci Suppl 31:536.

Marc RE (1986) Neurochemical stratification in the inner plexiform layer of the vertebrate retina. Vision Res 26:223-238.

Mariani AP, Hersh LB (1988) Synaptic organization of cholinergic amacrine cells in the rhesus monkey retina. J Comp Neurol 267:269280.

Masland RH, Mills JW, Cassidy C (1984) The functions of acetylcholine in the rabbit retina. Proc R Soc Lond [Biol] 223:121-139.

Matthew WD, Tsavaler L, Reichardt LF (1981) Identification of a synaptic vesicle-specific membrane protein with a wide distribution in neuronal and neurosecretory tissue. J Cell Biol 91:257-269.

Millar TJ, Ishimoto I, Chubb IW, Epstein ML, Johnson CD, Morgan IG (1987) Cholinergic amacrine cells of the chicken retina: a light and electron microscope immunocytochemical study. Neuroscience 21:725-743.

Miller RF, Bloomfield SA (1983) Electroanatomy of a unique amacrine cell in the rabbit retina. Proc Natl Acad Sci USA 80:3069-3073.
Mosinger J, Yazulla S (1985) Co-localization of GAD-like immunoreactivity and ${ }^{3} \mathrm{H}-\mathrm{GABA}$ uptake in amacrine cells of rabbit retina. $\mathbf{J}$ Comp Neurol 240:396-406.

Mosinger J, Yazulla S (1987) Double-label analysis of GAD- and GABA-like immunoreactivity in the rabbit retina. Vision Res 27:2330 .

Nichols RA, Sihra TS, Czernik AJ, Nairn AC, Greengard P (1990) Calcium/calmodulin-dependent protein kinase II increases glutamate and noradrenaline release from synaptosomes. Nature 343:647-651.

Obata K, Kojima N, Nishiye H, Inoue H, Shirao T, Fujita SC, Uchizono K (1987) Four synaptic vesicle-specific proteins: identification by monoclonal antibodies and distribution in the nervous tissue and the adrenal medulla. Brain Res 404:169-179.

O'Malley DM, Masland RH (1989) Co-release of acetylcholine and gamma-aminobutyric acid by a retinal neuron. Proc Natl Acad Sci USA 86:3414-3418.

Perin MS, Fried VA, Mignery GA, Jahn R, Sudhof TC (1990) Phospholipid binding by a synaptic vesicle protein homologous to the regulatory region of protein kinase $C$. Nature 345:260-263.

Perry VH, Walker M (1980) Amacrine cells, displaced amacrine cells and interplexiform cells in the retina of the rat. Proc $R$ Soc Lond [Biol] 208:415-431.

Peters A, Sethares C, Harriman KM (1990) Different kinds of axon terminals forming symmetric synapses with the cell bodies and initial axon segments of layer II/III pyramidal cells. II. Synaptic junctions. J Neurocytol 19:584-600.

Petrucci TC, Morrow JS (1987) Synapsin I: an actin-bundling protcin under phosphorylation control. J Cell Biol 105:1355-1363.

Ramón y Cajal S (1892) The structure of the retina (translated by SA Thorpe and M Glickstein, 1972). Springfield, MA: Thomas.

Rapisardi SC, Lipsenthal L (1984) Asymmetric and symmetric synaptic junctions in the dorsal lateral geniculate nucleus of cat and monkey. J Comp Neurol 224:415-424.

Raviola E, Raviola G (1982) Structure of the synaptic membranes in the inner plexiform layer of the retina: a freeze-fracture study in monkeys and rabbits. J Comp Neurol 209:233-248.

Reichardt LF, Kelly RB (1983) A molecular description of nerve terminal function. Annu Rev Biochem 52:871-926.

Schiebler W, Jahn R, Doucet JP, Rothlein J, Greengard P (1986) Characterization of synapsin I binding to small synaptic vesicles. J Biol Chem 261:8383-8390.

Solimena M, Folli F, Denis DS, Comi GC, Pozza G, De Camilli P, Vicari AM (1988) Autoantibodies to glutamic acid decarboxylase in a patient with stiff-man syndrome, epilepsy, and type I diabetes mellitus. N Engl J Med 318:1012-1020.

Südhof TC, Jahn R (1991) Proteins of synaptic vesicles involved in exocytosis and membrane recycling. Neuron 6:665-677.

Südhof TC, Czernik AJ, Kao HT, Takei K, Johnston PA, Horiuchi A Kanazir SD, Wagner MA, Perin MS, De Camilli P, Greengard P (1989) Synapsins: mosaics of shared and individual domains in a family of synaptic vesicle phosphoproteins. Science 245:1474-1480.

Tatsuoka H, Reese TS (1989) New structural features of synapses in the anteroventral cochlear nucleus prepared by direct freezing and freeze-substitution. J Comp Neurol 290:343-357.

Tauchi M, Masland RH (1984) The shape and arrangement of the cholinergic neurons in the rabbit retina. Proc R Soc Lond [Biol] 223: 101-119.

Thiel G, Sudhof TC, Greengard P (1990) Synapsin II. Mapping of a domain in the $\mathrm{NH}_{2}$-terminal region which binds to small synaptic vesicles. J Biol Chem 265:16527-16533.

Trimble WS, Cowan DM, Scheller RH (1988) VAMP-1: a synaptic vesicle-associated integral membrane protein. Proc Natl Acad Sci USA 85:4538-4542.

Trimble WS, Gray TS, Elferink LA, Wilson MC, Scheller RH (1990) Distinct patterns of expression of two VAMP genes within the rat brain. J Neurosci 10:1380-1387.

Uchizono K (1965) Characteristics of excitatory and inhibitory synapses in the central nervous system of the cat. Nature 207:642-643.

Valtorta F, Villa A, Jahn R, Dc Camilli P, Greengard P, Ceccarelli B (1988) Localization of synapsin I at the frog neuromuscular junction. Neuroscience 24:593-603.

Vaney DI, Young HM (1988) GABA-like immunoreactivity in cholinergic amacrine cells of the rabbit retina. Brain Res 438:369-373.

Vaughn JE, Famiglietti EVJ, Barber RP, Saito K, Roberts E, Ribak CE (1981) GABAergic amacrine cells in rat retina: immunocytochemical 
identification and synaptic connectivity. J Comp Neurol 197:113127.

Voigt $\mathrm{T}$ (1986) Cholinergic amacrine cells in the rat retina. J Comp Neurol 248:19-35.

Walaas SI, Browning MD, Greengard P (1988) Synapsin Ia, synapsin Ib, protein Illa, and protein IIIb, four related synaptic vesicle-associated phosphoproteins, share regional and cellular localization in rat brain. J Neurochem 51:1214-1220.
West RW (1976) Light and electron microscopy of the ground squirrel retina: functional considerations. J Comp Neurol 168:355-378.

Wiedenmann B, Franke WW (1985) Identification and localization of synaptophysin, an integral membrane glycoprotein of $M, 38,000$ characteristic of presynaptic vesicles. Cell 41:1017-1028. 